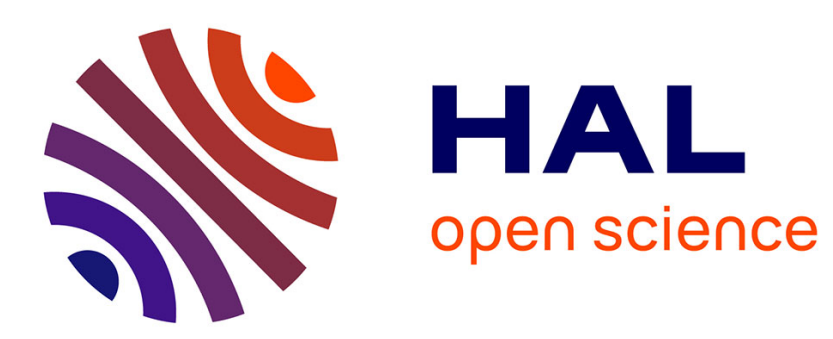

\title{
Small intestinal submucosa as a potential bioscaffold for intervertebral disc regeneration
}

Catherine Le Visage, Shu-Hua Yang, Leena Kadakia, Ann N Sieber, Kam W. Leong

\section{> To cite this version:}

Catherine Le Visage, Shu-Hua Yang, Leena Kadakia, Ann N Sieber, Kam W. Leong. Small intestinal submucosa as a potential bioscaffold for intervertebral disc regeneration. Spine, 2006, 31 (21), pp.242330. 10.1097/01.brs.0000238684.04792.eb . inserm-03288987

\section{HAL Id: inserm-03288987 https://www.hal.inserm.fr/inserm-03288987}

Submitted on 16 Jul 2021

HAL is a multi-disciplinary open access archive for the deposit and dissemination of scientific research documents, whether they are published or not. The documents may come from teaching and research institutions in France or abroad, or from public or private research centers.
L'archive ouverte pluridisciplinaire HAL, est destinée au dépôt et à la diffusion de documents scientifiques de niveau recherche, publiés ou non, émanant des établissements d'enseignement et de recherche français ou étrangers, des laboratoires publics ou privés. 


\section{S MALL INTES TINAL S UBMUCOSA AS A POTENTIAL B IOSCAFFOLD FOR INTERVERT EBRAL DIS C REGEN ERATION}

Catherine Le Visage $\mathrm{PhD}^{1}$, Shu-Hua Yang MD ${ }^{2}$, Leena Kadakia BS ${ }^{1}$, Ann N. Sieber MS ${ }^{2}$, John P. Kostuik $\mathrm{MD}^{2}$, Kam W. Leong $\mathrm{PhD}^{1}$

From the Departments of Biomedical Engineering ${ }^{1}$ and Orthopaedic Surgery ${ }^{2}$, Johns Hopkins School of Medicine, Baltimore, MD.

The manuscript submitted does not contain information about a medical device.

Running Head: A Bioscaffold for Disc Regeneration

Corresponding Author and Reprint Requests

Kam W. Leong, Ph.D.

Department of Biomedical Engineering, The Johns Hopkins School of Medicine

720, Rutland Avenue, Ross Building 726, Baltimore, Maryland, 21205

Phone: (410) 614-3741; Fax: (443) 287-3099; Email: kleong@bme.jhu.edu 
A Bioscaffold for Disc Regeneration

\begin{abstract}
Study Design. To evaluate the capacity of porcine Small Intestine Submucosa (SI S) to support the in vitro proliferation of human disc cells and the synthesis of extracellular matrix that could restore the biochemical properties of the disc.
\end{abstract}

Objectives. To evaluate if porcine SIS is a potential bioactive scaffold for rescuing degenerative disc cells.

Summary of Background Data. Discogenic back pain is associated with alterations of the disc and abnormal turnover of the disc extracellular matrix. We hypothesize that a biodegradable and biocompatible acellular scaffold such as SIS, which contains entrapped growth factors, may stimulate disc cells to synthesize extracellular matrix, thereby arresting the degeneration, or even promoting the regeneration, of the disc.

Methods. Human degenerative annulus and nucleus cells were seeded onto SIS scaffolds and evaluated over a 3-month period for cell growth (proliferation assay, DNA content) and matrix composition (glycosaminoglycan and collagen contents).

Results. More than $70 \%$ of seeded cells attached to the SIS surface and invaded throughout the scaffold, as revealed by H\&E staining. Macroscopic appearance of cell-seeded scaffolds was dramatically modified over time. Cell metabolic activity was confirmed for up to three months. Seeded scaffolds demonstrated a higher glycosaminoglycan content as compared to control scaffolds. Large areas of proteoglycans were detected by toluidine blue staining. Deposition of new extracellular matrix components was confirmed by positive gene expression for collagens I, II and X, aggrecan and Sox-9.

Conclusions. This pilot study shows that SIS is a promising bioactive material that could potentially serve as a temporary scaffold for intervertebral disc regeneration. 


\section{KEY WO RDS :}

intervertebral disc, tissue engineering, extracellular matrix, biodegradable implant

\section{KEY PO INTS :}

- Small Intestinal Mucosa (SIS) supported the growth of human degenerative disc cells for up to three months.

- Positive histology and gene expression confirmed the synthesis of new extracellular matrix components.

- SIS constitutes a promising biological scaffold that could potentially serve as a temporary scaffold for intervertebral disc regeneration. 
A Bioscaffold for Disc Regeneration

\section{KEY WO RDS :}

intervertebral disc, tissue engineering, extracellular matrix, biodegradable implant

\section{KEY PO INTS :}

- Small Intestinal Mucosa (SIS) supported the growth of human degenerative disc cells for up to three months.

- Positive histology and gene expression confirmed the synthesis of new extracellular matrix components.

- SIS constitutes a promising biological scaffold that could potentially serve as a temporary scaffold for intervertebral disc regeneration. 
A Bioscaffold for Disc Regeneration

\section{MINI ABSTRACT}

We evaluated porcine SIS as a biological scaffold for rescuing degenerative disc cells. Cell viability, phenotype maintenance and matrix synthesis were confirmed for more than three months. SIS is a promising biological material that could potentially serve as a temporary scaffold for intervertebral disc regeneration. 


\section{IN TRO DUC TIO N}

Spinal intervertebral discs contain a gelatinous nucleus, surrounded by a fibrous lamellar annulus. Both tissues contain an abundant matrix of negatively charged proteoglycans (PG) entangled with collagen fibers. This high content of proteoglycans is responsible for the ability of the discs to resist compressive forces applied to the spine. Progressive degeneration of intervertebral discs, associated with a modified turnover of the extracellular matrix, is a common feature of the aging population and may be a predominant cause of low back pain. Deterioration of the disc integrity can cause herniation and back pain. Current surgical management to relieve back pain includes lumbar discectomy, and fusion, of the painful motion segments.

Unlike conventional treatment options, biologic therapeutic approaches aim to stop/retard the degenerative process and to restore healthier discs, by transplantation of a matrix-rich tissue to the damaged disc. Such a biodegradable scaffold may provide support for cellular attachment as well as the desired biochemical microenvironment to promote specific gene expression and favorable extracellular matrix production.

SI S or Small Intestine Submucosa, harvested from the porcine small intestine and processed to remove the mucosa, has been used extensively as a soft tissue augmentation device. ${ }^{1}$ The resulting thin acellular membrane is a loose extracellular matrix scaffold composed of $80-90 \%$ collagen in the form of oriented fibers giving rise to longitudinal tensile properties, and contains glycosaminoglycans as well as entrapped growth factors such as basic fibroblast growthfactor (bFGF), vascular endothelial cell growth factor (VEGF) and transforming growth factor $(\mathrm{TGF}-\beta) .^{2.4}$ When surgically implanted, this biocompatible and biodegradable scaffold provides strength for reinforcement of damaged or weakened soft tissues, and constitutes an alternative to auto- or allograft. It has been used for replacement of blood vessels and bladder defects. ${ }^{5,6}$ Moreover, SIS promotes cell proliferation/differentiation and induces synthesis of a new tissue structurally and functionally similar to the original damaged tissue. ${ }^{1}$ SIS has been shown to be entirely resorbed 3 months after implantation in the bladder of dogs and replaced by 
deposition of a new host extracellular matrix through the body's natural healing process, with successful replacement of the damaged urinary tissue. ${ }^{7}$ In musculoskeletal applications, SIS has been used to promotetissue regeneration in rotator cuffs, knee ligaments, tendons and menisci. ${ }^{8-10}$

Because of its porous structure and the entrapped growth factors, we hypothesize that SIS would be an attractive substrate for disc cells and a potential bioscaffold for repair of the degenerative disc. We speculate that this scaffold may stimulate the in situ disc cells to proliferate and synthesize a new extracellular matrix, thereby forestalling the depletion of proteoglycans from the nucleus and arresting the degeneration, or even promoting the regeneration, of the disc by maintaining adequate mechanical properties.The accumulation of new extracellular matrix would eventually generate a tissue whose properties would mimic those of a normal disc. As a first step towards accomplishing this goal, we investigated in this pilot study the culture of human degenerative disc cells in small intestine submucosa (SIS) in terms of cell viability and proliferation, synthesis of glycosaminoglycans (GAGs) and collagen and gene expression. 
A Bioscaffold for Disc Regeneration

\section{METHO DS}

\section{Disc Cell Culture}

Human nucleus pulposus (NP) and annulus fibrosis (AF) cells were isolated from surgical specimens obtained from three patients who underwent surgery for degenerative disease of the lumbar spine. Cartilaginous endplate tissues were carefully removed from the disc tissue specimens and disc cells were isolated with DNAse and collagenase digestion. ${ }^{11}$ Cells were plated in $75 \mathrm{~cm}^{2}$ plates (Falcon, Franklin Lakes, NJ) at a density of $2.5 \times 10^{4}$ cells $/ \mathrm{mL}$ and expanded for 2 to 3 weeks in a $5 \% \mathrm{CO} 2$ incubator in a humidified atmosphere as described previously. ${ }^{11,12}$

\section{Cell seeding on scaffolds}

Porcine small intestine submucosa was prepared by DePuy AcroMed (Raynham, MA), processed for disinfection with $0.1 \%$ peracetic acid in ethanol, rinsed in distilled water and stored at $4^{\circ} \mathrm{C}$ until use. SI S membranes $\left(\sim 5 \mathrm{~cm}^{2} \times 200 \mu \mathrm{m}\right.$ thick) were seeded with either nucleus pulposus (NP) cells or annulus fibrosus (AF) cells $\left(4 \times 10^{6}\right.$ cells). Culture medium consisted of DMEM/F12 containing $10 \%$ of serum and was changed 3 times a week. Non attached cells were counted in culture medium one day after seeding. The samples were harvested after culturing in 6-well plates for one, two or three months. Two to five replicates of each disc donor cell population were tested in this study. Non-seeded SI S scaffolds incubated in culture medium served as controls.

\section{Biochemical assays}

After one, two or three months of culture, the wet and dry weights of the SIS scaffolds were recorded and the water content was calculated. The cellular metabolic activity was evaluated by a WST -1 assay (Roche Molecular Biochemicals, Indianapolis, IN). For DNA quantification, SIS scaffolds were dige sted with 20 units $/ \mathrm{mL}$ papain (Worthington, Lakewood, NJ) at $60^{\circ} \mathrm{C}$ overnight. Ten $\mu \mathrm{L}$ samples were added to $190 \mu \mathrm{L}$ of PicoGreen DNA Reagent (Molecular Probes, Eugene, OR) and DNA concentrations were 
determined by a fluorometric assay (excitation $502 \mathrm{~nm}$, emission $523 \mathrm{~nm}$ ) against DNA standards ranging from 1 to $1000 \mathrm{ng} / \mathrm{mL}$.

Aliquots from the papain-digested SI S scaffolds were assayed for glycosaminoglycan content with a solution of 1,9-dimethylmethylene blue (DMMB) dye at $\mathrm{pH} 3 .{ }^{13}$ Forty $\mu \mathrm{L}$ samples were added to $250 \mu \mathrm{L}$ of DMMB in a 96 well-microplate and absorbance at $570 \mathrm{~nm}$ was read in a microplate reader. Glycosaminoglycan content was determined against chondroitin-4 sulfate standards (Accurate Chemical, Westbury, NY) ranging from 5 to $40 \mu \mathrm{g} / \mathrm{ml}$. Results were expressed as the amount of glycosaminoglycan per SIS scaffold after normalization with the wet weight. Acid hydrolysis of collagen in papain-digested scaffolds was performed in $\mathrm{HCl}(6 \mathrm{~N})$ at $110^{\circ} \mathrm{C}$. Hydroxyproline was reacted with Erlich's Reagent at $60^{\circ} \mathrm{C}$ for thirty minutes and absorbance at $570 \mathrm{~nm}$ was read. Hydroxyproline content was determined from a standard curve of hydroxyproline (Sigma, St.Louis, MO) in water ranging from 1 to $50 \mu \mathrm{g} / \mathrm{mL}$. Results were expressed as hydroxyproline content per SIS scaffold after normalization with the wet weight.

\section{Histology}

After fixation in $10 \%$ formalin, SIS scaffolds were paraffin embedded and sectioned. H\&E and toluidine blue staining were performed.

\section{RNA Analysis}

Total RNA was isolated from SIS scaffolds using a RNeasy Mini Kit (Quiagen, Valencia, CA). The reverse transcription and PCR were carried out with the QIAGEN OneStep RT-PCR Kit (Quiagen, Valencia, CA) and with the following primers (IDT, Coralville, IA): collagen I (forward F: 5'TGACGA GACCAAGAACT G-3', reverse R: 5'-CCATCCAAACCACTGAAACC-3'); collagen II e2 (F: 5'-AGGA GGCT GGCA GCT GT GT GC-3'， R: 5'-CACT GGCA GT GGCGA GGTCAG-3'); collagen X (F: 5'-CCCTTTTT GCT GCT AGT AT CC-3'， R: 5'-CT GTT GT CCAGGTTTTCCT GGCAC-3'); aggrecan (F: 5'-GCCTT GAGCA GT T CACCTT C-3'， R: 5'-CT CTTCT ACGGGGACA GCAG-3'); Sox-9 （F : 5'ACGT CAT CT CCAACAT CGAGACC-3', R: 5'-CT GT AGT GT GGGA GGTT GAAGGG-3'). Human act in 
(Clontech, Palo Alto, CA) was used as the control. Thirty cycles of PCR were carried out on a Techgene Thermal and the resulting products were analyzed by $1.2 \%$ agarose gel electrophoresis then imaged with a Versadoc Imaging System (Biorad).

\section{Western-blot}

For Western-blot analysis, SIS scaffolds proteins were extracted in $500 \mu \mathrm{L}$ of $4 \mathrm{M}$ guanidine- $\mathrm{HCl}$ at $4{ }^{\circ} \mathrm{C}$ overnight. Protein samples were electrophoresed on $12 \%$ SDS-PAGE gel then transferred to PVDF membranes. After blocking overnight with $5 \%$ non fat dry milk, membranes were probed with either a mouse anti-human Collagen Type I antibody (\#CP17L, Oncogene, San Diego, CA) or a mouse antihuman Collagen Type II antibody (\#CP18L, Oncogene, San Diego, CA), followed by a goat Anti-Mouse HRP conjugate (71045-3, Oncogene/Novagen, San Diego, CA), detected with a chemiluminescent detection kit (Amersham ECL PLUS) and then imaged with a Versadoc Imaging System (Biorad, Hercules, CA).

\section{Statistical Analysis}

Statistical analysis was performed with a Student $\mathrm{t}$ test and $\mathrm{p}<0.05$ was considered significant. 


\section{RESULTS}

The initial acellular scaffold used in this study (Fig. 1A) consisted of a single-layered, thin extracellular matrix membrane, on which disc cells were seeded as a suspension. On day one, more than $70 \%$ of disc cells attached to the scaffold. We thus assumed that 2.8 million cells were at tached to the scaffold, even though some could have been only closely associated and might have detached later on during the experiment Gross appearance of the SIS scaffolds seeded with disc cells changed over time, showing significant folding and shrinkage (Fig. 1C) as compared to the control scaffold (Fig. 1B) (both scaffolds were incubated in medium for two months). Examination of H\&E stained sections of seeded scaffolds revealed clusters of cells in the folded areas, as well as cells present on the surface of the scaffold. After one month, cells appeared mainly on the edges of the scaffold, whereas at later time points cells that migrated throughout the scaffold were observed deeper in the SIS (Fig. 1D).

Water content (Fig. 2) increased in all scaffolds as compared to the initial scaffold (88.4\%, data not shown). No significant differences were found between the water content of non seeded and seeded scaffolds. For clarity purpose, all subsequent results were expressed as a function of the wet weight of the scaffolds unless otherwise mentioned.

Metabolic activity of the seeded cells was assessed with an assay based on the cleavage of a tetrazolium salt by the dehydrogenase and the release of a water soluble formazan. Both NP and AF cells cultured in SIS scaffolds remained viable and metabolically active for the duration of experiment (up to three months) (Fig.3A). No significant differences between AF cells and NP cells were found. There was also no significant difference between the time points. DNA content, as an estimation of the cell number, slightly decreased after three-month culture of the AF cells (Fig.3B), but overall, the ratio of metabolic activity/cell number remained constant (Fig.3C). Similar metabolic activity and DNA content results were obtained for NP cells (data not shown). 
Glycosaminoglycan (GAG) content was evaluated in all scaffolds and standardized with the wet weight. Even though all SI S samples initially contained glycosaminoglycans (466 $\mu \mathrm{g} / \mathrm{g}$, data not shown), seeded scaffolds demonstrated a higher GAG content as compared to control SIS, as illustrated on Fig.4A and 4B for AF cells and NP cells, respectively. Control scaffolds experienced a massive loss of glycosaminoglycans during the first two months of culture, before reaching a stable low GAG content after 3 months. Significant differences with controls were achieved for AF cells after one and two months of culture $(571 \pm 51 \mu \mathrm{g} / \mathrm{g}$ vs $338 \pm 113 \mu \mathrm{g} / \mathrm{g}$ and $496 \pm 97 \mu \mathrm{g} / \mathrm{g}$ vs $236 \pm 60 \mu \mathrm{g} / \mathrm{g}$, respectively). As a matter of interest, NP cells needed two months of culture to reach statistical differences with controls (416 84 $\mu \mathrm{g} / \mathrm{g}$ vs $236 \pm 60 \mu \mathrm{g} / \mathrm{g})$. Loss of GAGs from initial SIS scaffold was delayed by synthesis of new glycosaminoglycans by AF cells, and even compensated by synthesis from NP cells. Addition of disc cells to the SIS scaffolds resulted in an increase of the GAG content of up to $200 \%$ for AF cells after two months and $180 \%$ for NP cells after three months. Even though NP cells appeared to be less effect ive than AF cells in synthesizing new glycosaminoglycans, with a resulting lower GAG content, the difference between the cultured scaffolds and the controls scaffolds showed a continuous increase over time in the case of the NP cells (Fig. 4C), from $55 \mu \mathrm{g} / \mathrm{g}$ at one month to $183 \mu \mathrm{g} / \mathrm{g}$ at three months. No difference in collagen content was found between control and scaffolds seeded with either AF cells (Fig.5) or NP cells (data not shown).

Positive toluidine blue staining, indicating the presence of glycosaminoglycans, was observed on both seeded and control scaffolds sections (Fig. 6A and 6B, respectively), even though the staining was less intense for the control scaffolds. Large areas of glycosaminoglycans observed on seeded scaffolds, as shown on Fig. 6C and 6D, indicate the deposition of extracellular matrix, since no similar areas were ever found in control scaffolds. Accumulation of cells was associated with these glycosaminoglycans-rich areas.

PCR analysis conducted on SIS scaffolds seeded with nucleus cells is presented on Fig.7. Collagen Type I expression was positive in all samples. Collagen Type II and X were positive in most samples, 
although the signal for type $\mathrm{X}$ was weak. Aggrecan expression was positive at one month and then at three months. Expression of Sox-9 was never positive at one month but visible at the two- or three-month time points. A similar gene expression profile was obtained with scaffolds seeded with annulus cells (data not shown). Westem blot analysis of proteins extracted from the seeded SI S confirmed the synthesis of both collagen type I and type II molecules (dat not shown). 


\section{DISC USS IO N}

The motivation of this study was to evaluate if SIS would be a suitable scaffold for culturing disc cells, as the first step of applying a biological scaffold to stimulate regeneration of the disc. Monolayer culture of disc cells has been described as a technique of expanding the cell number for in vitro experiments, rather than enabling matrix synthesis. Three-dimensional culture, which stabilizes the shape and cytoskeleton of disc cells, is required for the long term maintenance of their morphology and phenotypes. ${ }^{14,15}$ Several scaffolds have been studied for the culture of human disc cells isolated from degenerative discs, either for investigation of their metabolism or as a template for disc engineering. However, Gruber et al. show that a cell carrier without additional growth factors would not enhance significantly the extracellular matrix synthesis by disc cells. ${ }^{16}$ ECM production or ECM gene expression are rather low in collagen gels, and low as well in alginate, agarose and fibrin constructs, indicat ing the need for additional growth factors and cytokines to enhance the matrix synthesis by degenerative disc cells. ${ }^{16}$ In this study, the SIS membrane is a loose extracellular matrix scaffold composed of collagen, glycosaminoglycans and growth factors. Extracellular matrix is a reservoir of many signaling factors involved in biological functions such as angiogenesis, inflammation, cell migration, and injury repair. ${ }^{17}$ One intriguing feature of SIS is its embedded biological molecules. Even though the SIS preparation method includes processes such as acellularization, sterilization and lyophilization, this scaffold still retains some active growth factors that can contribute to its biological activity. ${ }^{2}$

We have demonstrated that SIS can support the viability and proliferation of both NP cells and AF cells for up to three months in culture. Histology evidence on H\&E-stained sections confirmed the attachment and migration of the disc cells into the scaffold. Structurally, SIS scaffolds exhibit two different sides, one rough and one smooth. In vitro attachment of other cell types has been shown to be restricted to the rough serosal side of SIS, as the mucosal side limits the invasion of the scaffold. ${ }^{18}$ However, in this experiment disc cells were able to attach to both sides and some cells were found distributed throughout the scaffold. 
Over time we observed a slight decrease in DNA content in all samples. A similar decline in cell content was previously reported for nucleus cells cultured on collagen scaffolds. ${ }^{19,20}$ This decrease of cellularity may have been due to apoptosis-induced cell death. Loosely at tached cells on the surface of the membrane blocking the migration of the cells into the scaffold may have also contributed to this decrease in cellularity.

When a highly porous collagen scaffold was used to engineer an intervertebral disc-like matrix, a loss of newly synthesized proteoglycans in the culture medium was reported. ${ }^{19}$ This high porosity scaffold was selected as a way to enhance the initial cell seeding efficacy but eventually led to a loss of more than $60 \%$ of the proteoglycans synthesized. In our study, control SIS scaffolds incubated in medium lost significant amounts of glycosaminoglycans over time. However, we were not able to detect any glycosaminoglycans in the culture medium of these control scaffolds, or from any seeded scaffolds, probably because of the large volume of culture medium used in our protocol. By comparison with control scaffolds, disc cells seeding on SIS resulted in a net increase of glycosaminoglycans in the scaffold. Addition of TGF- $\beta$ to the culture medium has been shown in vitro to promote matrix synthesis and increased accumulation of proteoglycans ${ }^{19}$. Thus, TGF- $\beta$ associated with the SIS scaffold may have promoted the synthesis of proteoglycans by disc cells. Even though the loss of some of the newly synthesized matrix molecules while culturing in vitro may occur, the in vivo situation most certainly would be different. After in vivo implantation into the nucleus, a more confined environment would limit the loss of glycosaminoglycans and the resulting matrix accumulation could be greater.

In this study the NP cells and AF cells differed with respect to their ability to accumulate extracellular matrix components. The highest GAG content was reached with AF cells cultured for two months, while a continuous increase was observed for NP cells. Moreover, the GAG content obtained by culturing NP cells was lower than that with AF cells, as reported in a three-dimensional environment of agarose gel. ${ }^{15}$ However, the progressive and significant increase of the GA G content when culturing NP cells suggest that the slow and continuous release of growth factors associated with SIS might have 
explained the effect on the NP cells. The major feature of the SIS is its ability to deliver a variety of growth factors to the cells. We did not compare the SIS to other scaffolds because such comparison would be difficult, requiring a chemical or physical process to remove all the growth factors without damaging the structural assembly of the collagen fibers in the SIS.

The effect of such growth factors on disc cells was also evidenced by studying their gene expression profile over time. First of all, AF cells and NP cells retained over a 3-month culture their chondrocytic phenotype. $^{21}$ Disc cells, as well as chondrocytes, reportedly cease to express cartilage-specific markers when cultured in a monolayer and later on assume a fibroblastic appearance. This can be reversed by transferring them back to a three-dimensional environment such as alginate gels, or in our case, SIS scaffold. The ability of annulus cells to synthesize a new matrix whose properties resemble those of the nucleus pulposus demonstrate that regeneration from available in situ cells could take place even if nucleus cells were absent. One drawback of the use of annulus cells is their association with collagen type I synthesis rather than collagen type II. However, in vitro, both types of collagen gene expression were detected from annulus cells, although the collagen type II expression could not be detected in all samples at all time points. The decrease of Sox-9 expression has been reported to be associated with disc degeneration and decreased collagen type II gene expression. ${ }^{22}$ Even though sox -9 was not detected at the early time points, it was detected in the 3-month scaffolds, suggesting a possible regeneration mechanism that would restore a normal gene expression profile of these disc cells. Moreover, the late expression of collagen type $\mathrm{X}$, which has been described as an indication of repair or remodeling of the $\operatorname{disc}^{23}$, was observed.

SIS is a promising biological material that could potentially serve as a temporary scaffold for intervertebral nucleus regeneration. In vitro, SIS scaffold supported the growth of human degenerative disc cells and provided the necessary biochemical environment and growth factors for a sustained synthesis of GAGs over a three-month period. Positive histology and gene expression confirmed the production of new extracellular matrix components that might restore the biochemical properties and 
functions of the human intervert ebrate nucleus. SI S provides both the three-dimensional environment and the released growth factors to the disc cells, the major feature of the SIS being its ability to deliver a variety of growth factors to the cells. It is important to note the consistency of the findings from culturing degenerative disc cells harvested from three patients, considering the fact that these cells certainly differ in their degenerative state. This would bode well for possible future clinical applications, where implantation of the SIS scaffold can take place without having to first assess in vitro the proliferative capacity of the cells. Ongoing in vivo experiments in a rabbit model aim to determine the fate of SIS implanted into a degenerative disc as well as the restoration of the biomechanical properties of the disc. 


\section{LEG ENDS}

Figure 1. Small intestine submucosa (SI S) scaffold before seeding consisted of a thin extracellular matrix membrane (surface $5 \mathrm{~cm}^{2}$ ) (A). Control scaffold incubated in culture medium remained as a flat membrane (B) while the macroscopic appearance of scaffold seeded with annulus cells showed shrinkage and folding areas (C). H\&E staining of scaffold sections revealed that the disc cells (arrows) attached and migrated throughout the scaffold (D). Similar shapes were observed at all time points for the scaffolds cultured with annulus or nucleus cells. Seeded sample shown was cultured for 2 months. Bar represents 100 microns.

Figure 2. Water content of small intestine submucosa (SIS) scaffolds was calculated after measurement of both wet and dry weights and expressed as a percentage. Data represent the mean of at least 3 experiments \pm SEM.

$* \mathrm{p} \varangle 0.05$ for 1 month scaffolds seeded with annulus fibrosus (AF) cells compared to control scaffolds.

Figure 3. (A) Metabolic activity of annulus fibrosus (AF) cells, seeded on the small intestine submucosa (SIS) scaffolds, was measured with a W st-1 assay. Results are expressed as the ratio of optical densities at $450 \mathrm{~nm}$ per scaffold wet weight (ww) (B) DNA content of SIS scaffolds seeded with AF cells, expressed in $\mu \mathrm{g}$ of DNA per scaffold wet weight (ww) (C) Ratio of metabolic activity/ DNA content of AF cells seeded on SIS scaffold. For all three graphs, data represented is the mean of at least 3 experiments \pm SEM. No significant difference was found between the time points.

Figure 4. Glycosaminoglycan (GAG) content of small intestine submucosa (SIS) scaffolds, seeded with annulus fibrosus (AF) cells (A) or nucleus pulposus (NP) cells (B), was measured with a dimethylmethylene blue assay and expressed in $\mu \mathrm{g} / \mathrm{g}$ wet weight (ww) of scaffolds. Control SIS scaffolds 
versus seeded scaffolds, $* \mathrm{p}<0.001, * * \mathrm{p}<0.01$. (C) Difference in GAG content between control and scaffolds seeded with AF cells or NP cells. Data represent the mean of separate experiments conducted with cells from 3 patients \pm SEM. Increase in GAG content between 1 month and 2 months $* * * p<0.05$.

Figure 5. Hydroxyproline content of control scaffolds and scaffolds seeded with annulus fibrosus (AF) cells was measured with a colorimetric assay and expressed in $\mu \mathrm{g} / \mathrm{g}$ of wet weight (WW). Data represents the mean of separate experiments conducted with cells from 3 patients \pm SEM.

Figure 6. Toluidine blue staining of paraffin sections of seeded scaffold (A) versus control scaffold (B), which presented a disrupted structure after incubation in medium for three months. Some glycosaminoglycan-rich areas were observed (C and D) for seeded scaffolds. Bar represents 100 microns. Arrows indicate glycosaminoglycans-rich areas.

Figure 7. RNA extracted from nucleus pulposus (NP) cells, cultured on small intestine submucosa (SIS) scaffolds for 1, 2 and 3 months, was analyzed by PCR for the following genes: collagen type I, II and X, aggrecan and Sox 9 . 
A Bioscaffold for Disc Regeneration

\section{REFERENCES}

1. Badylak S, Kokini K, Tullius B, et al. Morphologic Study of Small Intestinal Submucosa as a Body

Wall Repair Device. J Surg Res 2002;103:190-202.

2. McDevitt CA, Wildey GM, Cutrone RM. Transforming Growth Factor-Beta1 in a Sterilized Tissue

Derived from the Pig Small Intestine Submucosa. J Biomed Mater Res 2003;67A:637-40.

3. Voytik-Harbin SL, Brightman AO, Kraine MR, et al. Identification of Extractable Growth Factors from

Small Intestinal Submucosa. J Cell Biochem 1997;67:478-91.

4. Hodde JP, Record RD, Liang HA, et al. Vascular Endothelial Growth Factor in Porcine-Derived

Extracellular Matrix. Endothelium 2001;8:11-24.

5. Kim SS, Kaihara S, Benvenuto MS, et al. Small Intestinal Submucosa as a Small-Caliber Venous

Graft: A Novel Model for Hepatocyte Transplantation on Synthetic Biodegradable Polymer Scaffolds

with Direct Access to the Portal Venous System. J Pediatr Surg 1999;34:124-8.

6. Sofer M, Rowe E, Forder DM, et al. Ureteral Segmental Replacement Using MultilayerPorcine SmallIntestinal Submucosa. J Endourol 2002;16:27-31.

7. Record RD, Hillegonds D, Simmons C, et al. In Vivo Degradation of 14c-Labeled Small Intestinal Submucosa (Sis) When Used for Urinary Bladder Repair. Biomaterials 2001;22:2653-9. 
A Bioscaffold for Disc Regeneration

8. Musahl V, Abramowitch SD, Gilbert TW, et al. The Use of Porcine Small Intestinal Submucosa to

Enhance the Healing of the Medial Collateral Ligament--a FunctionalTissue Engineering Study in

Rabbits. J Orthop Res 2004;22:214-20.

9. Cook JL, Tomlinson JL, Amoczky SP, et al. Kinetic Study of the Replacement of Porcine Small

Intestinal Submucosa Grafts and the Regeneration of Meniscal-Like Tissue in Large Avascular Meniscal

Defects in Dogs. Tissue Eng 2001;7:321-34.

10. Welch JA, Montgomery RD, Lenz SD, et al. Evaluation of Small-Intestinal Submucosa Implants for

Repair of Meniscal Defects in Dogs. Am J Vet Res 2002;63:427-31.

11. Maldonado BA, Oegema TR, Jr. Initial Characterization of the Metabolism of Intervertebral Disc

Cells Encapsulated in Microspheres. J Orthop Res 1992;10:677-90.

12. Chiba K, Andersson GB, Masuda K, et al. A New Culture System to Study the Metabolism of the

Intervertebral Disc in Vitro. Spine 1998;23:1821-7.

13. Enobakhare BO, Bader DL, Lee DA. Quantification of Sulfated Glycosaminoglycans in

Chondrocyte/Alginate Cultures by Use of 1,9-Dimethylmethylene Blue. Anal Biochem 1996;243:189-91.

14. Gruber HE, Hanley EN, Jr. Human Disc Cells in Monolayer Vs 3d Culture: Cell Shape, Division and

Matrix Formation. BMC Musculoskelet Disord 2000;1:1. 
A Bioscaffold for Disc Regeneration

15. Sato M, Kikuchi T, Asazuma T, et al. Glycosaminoglycan Accumulation in Primary Culture of Rabbit Intervertebral Disc Cells. Spine 2001;26:2653-60.

16. Gruber HE, Leslie K, Ingram J, et al. Cell-Based Tissue Engineering for the Intervertebral Disc: In Vitro Studies of Human Disc Cell Gene Expression and Matrix Production within Selected Cell Carriers.

Spine J 2004;4:44-55.

17. Badylak SF. The Extracellular Matrix as a Scaffold for Tissue Reconstruction. Sem in Cell Dev Biol 2002;13:377-83.

18. Badylak S, Liang A, Record R, et al. Endothelial Cell Adherence to Small Intestinal Submucosa: An Acellular Bioscaffold. Biomaterials 1999;20:2257-63.

19. Alini M, Li W, Markovic P, et al. The Potential and Limitations of a Cell-Seeded

Collagen/Hyaluronan Scaffold to Engineer an Intervertebral Disc-Like Matrix. Spine 2003;28:446-54.

20. Sun Y, Hurtig M, Pilliar RM, et al. Characterization of Nucleus Pulposus-LikeT issue Formed in Vitro. JOrthop Res 2001;19:1078-84.

21. Sive JI, Baird P, Jeziorsk M, et al. Expression of Chondrocyte Markers by Cells of Normal and Degenerate Intervertebral Discs. Mol Pathol 2002;55:91-7.

22. Kim KS, Yoon ST, Park JS, et al. Inhibition of Proteoglycan and Type Ii Collagen Synthesis of Disc Nucleus Cells by Nicotine. J Neurosurg 2003;99:291-7. 
A Bioscaffold for Disc Regeneration

23. Roberts S, Bains MA, Kwan A, et al. Type X Collagen in the Human Invertebral Disc: An Indication of Repair or Remodelling? Histochem J 1998;30:89-95. 
Fig.1
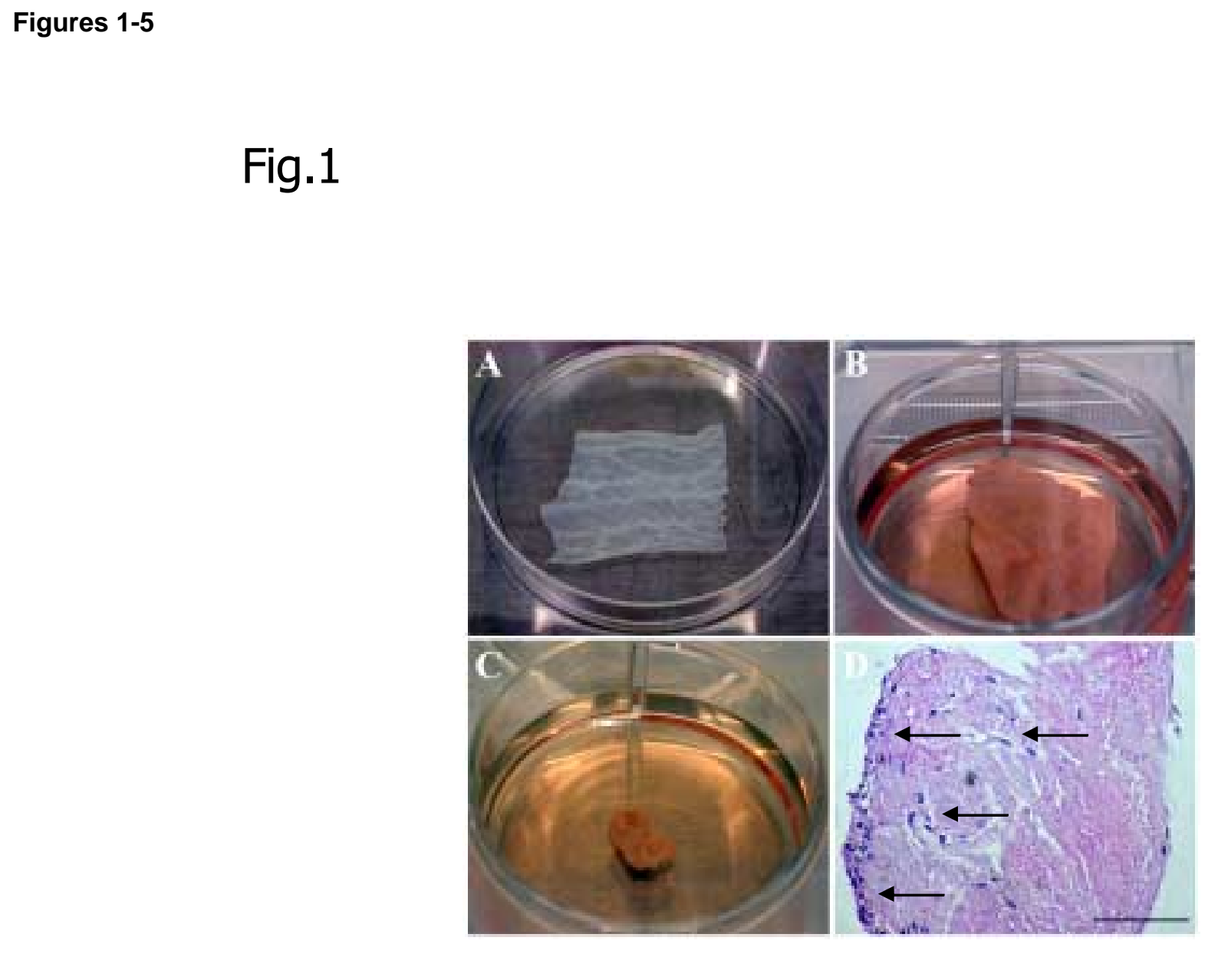

Figures 1-5

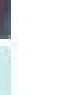

$$
\text { . }
$$

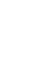


Fig.2

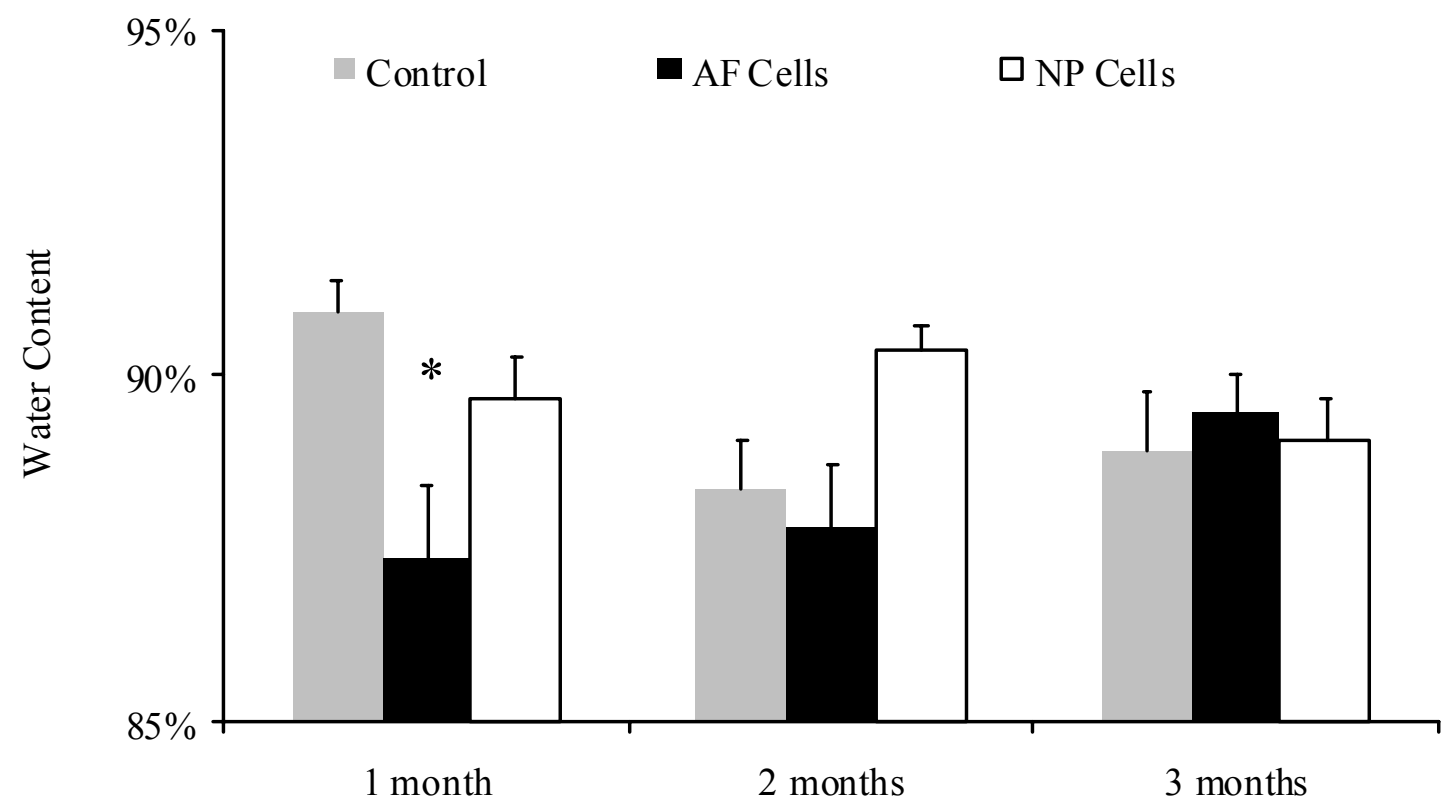


Fig.3
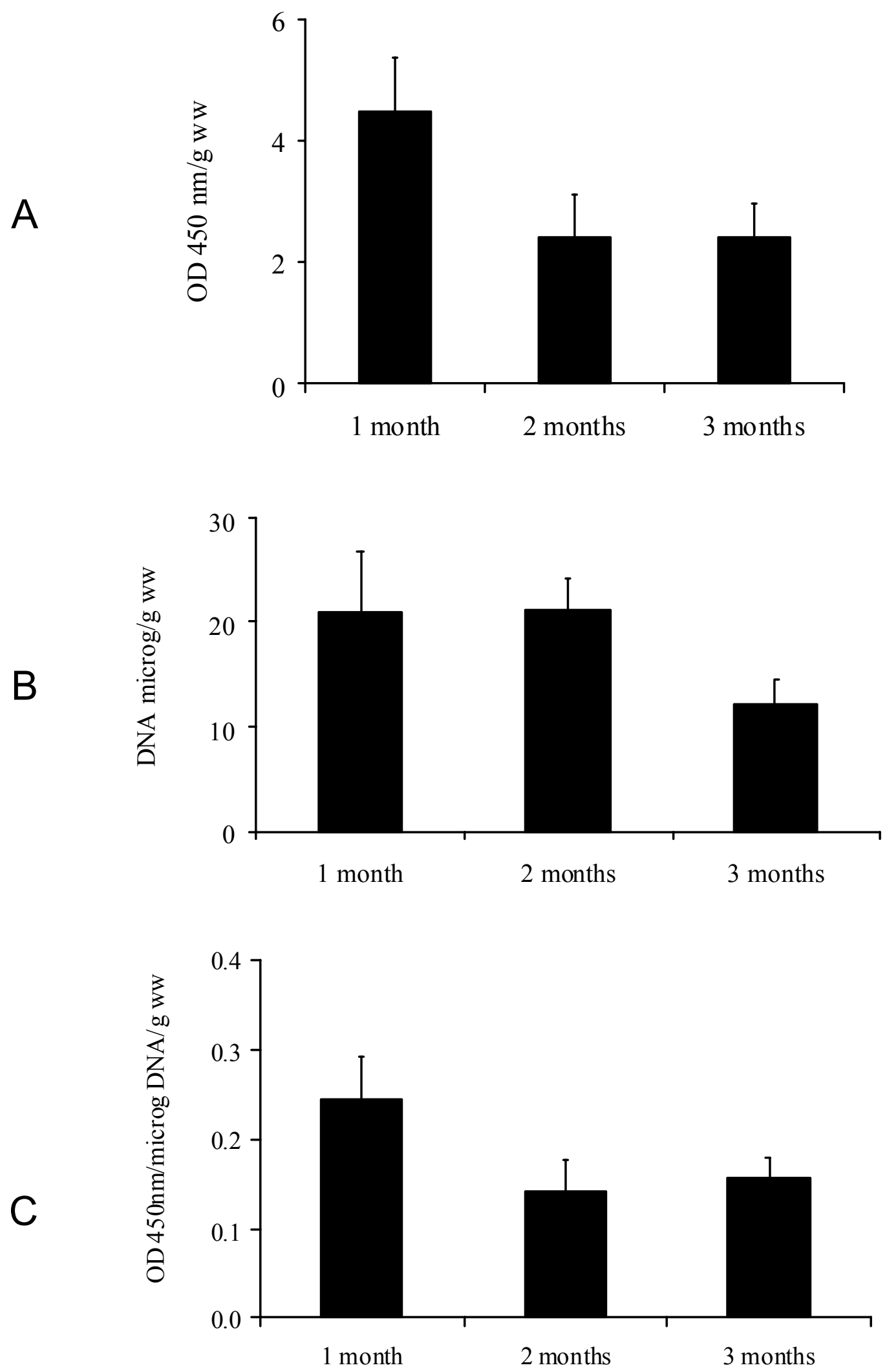
Fig.4
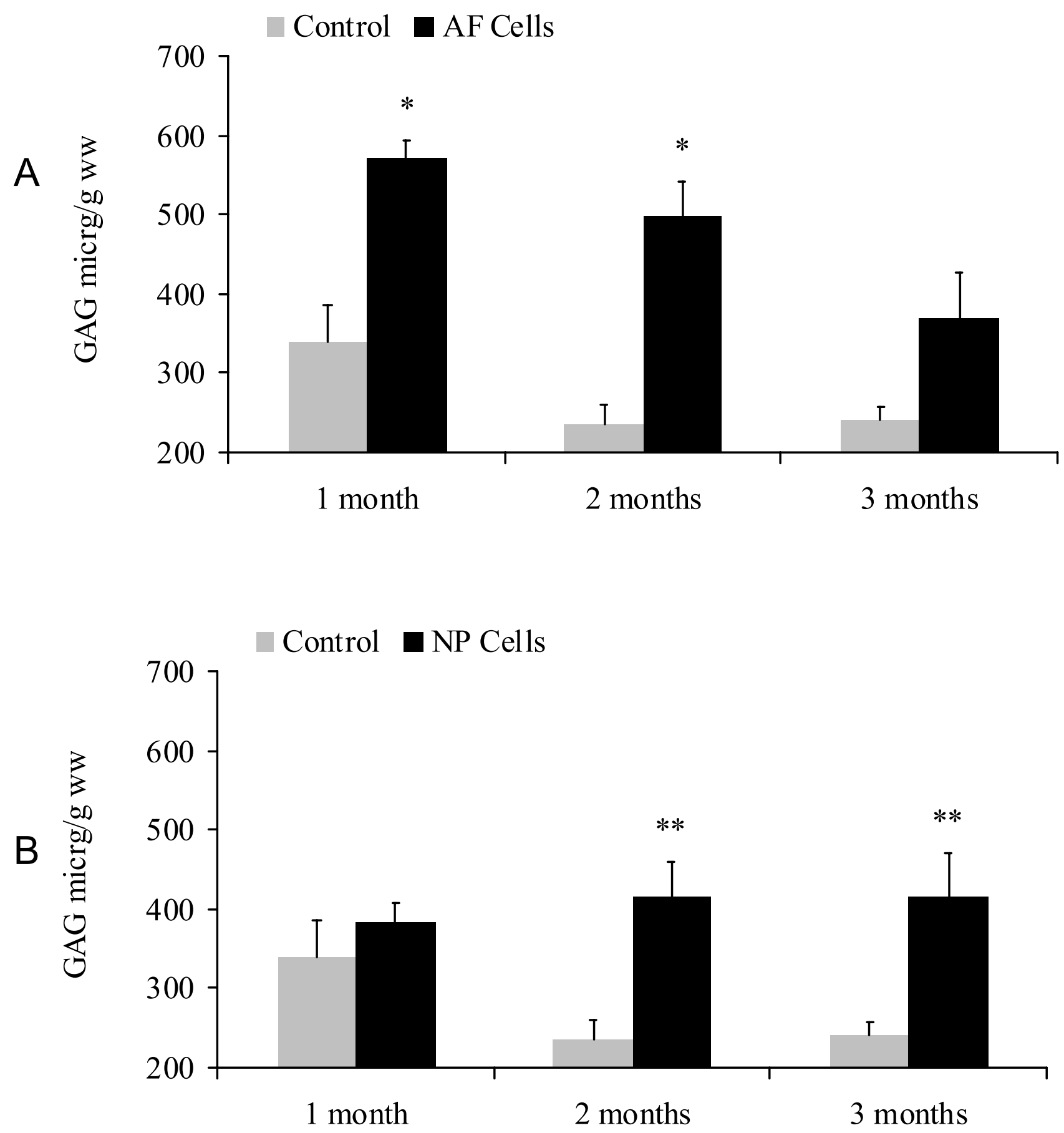


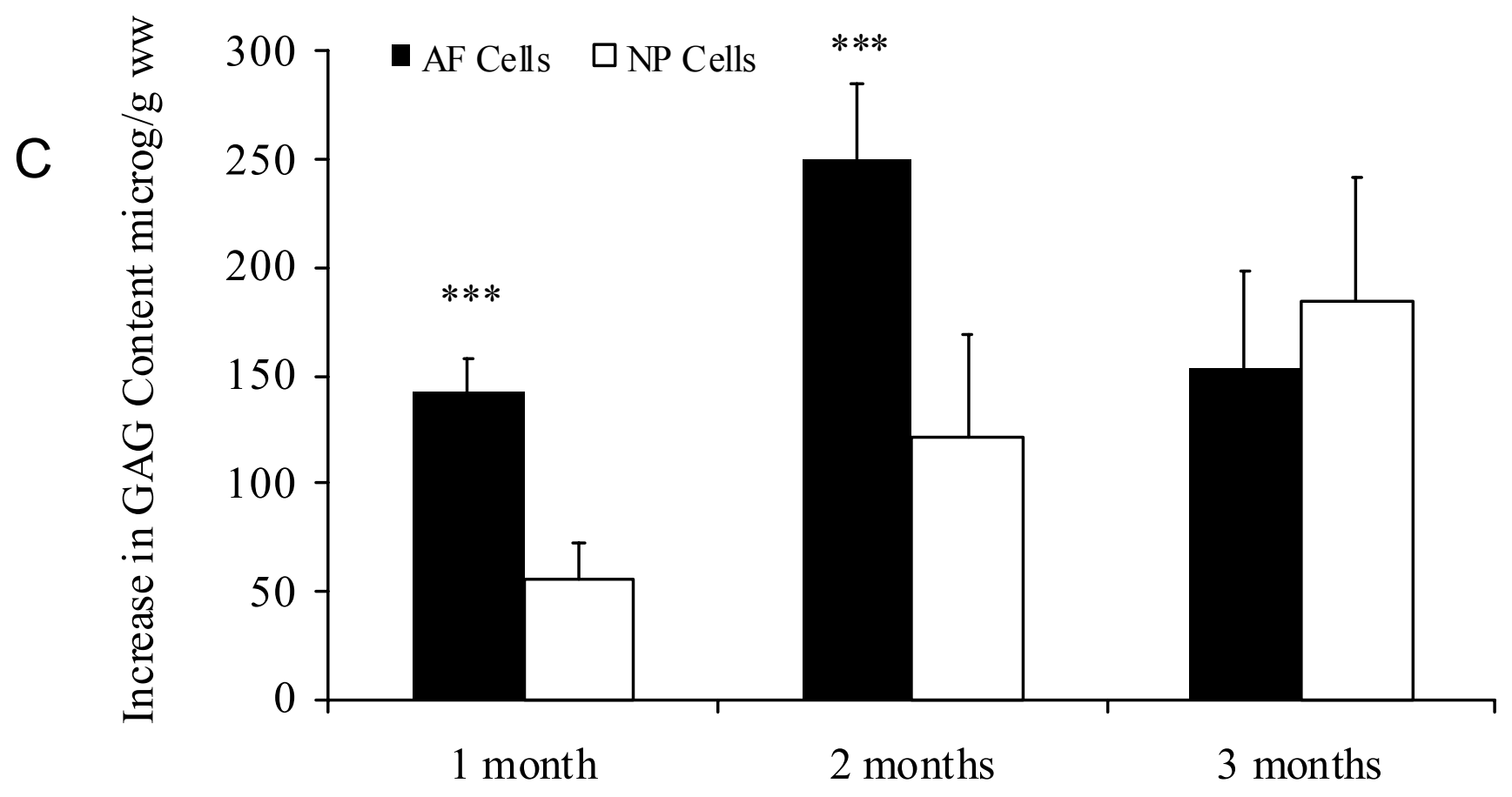


Fig.5

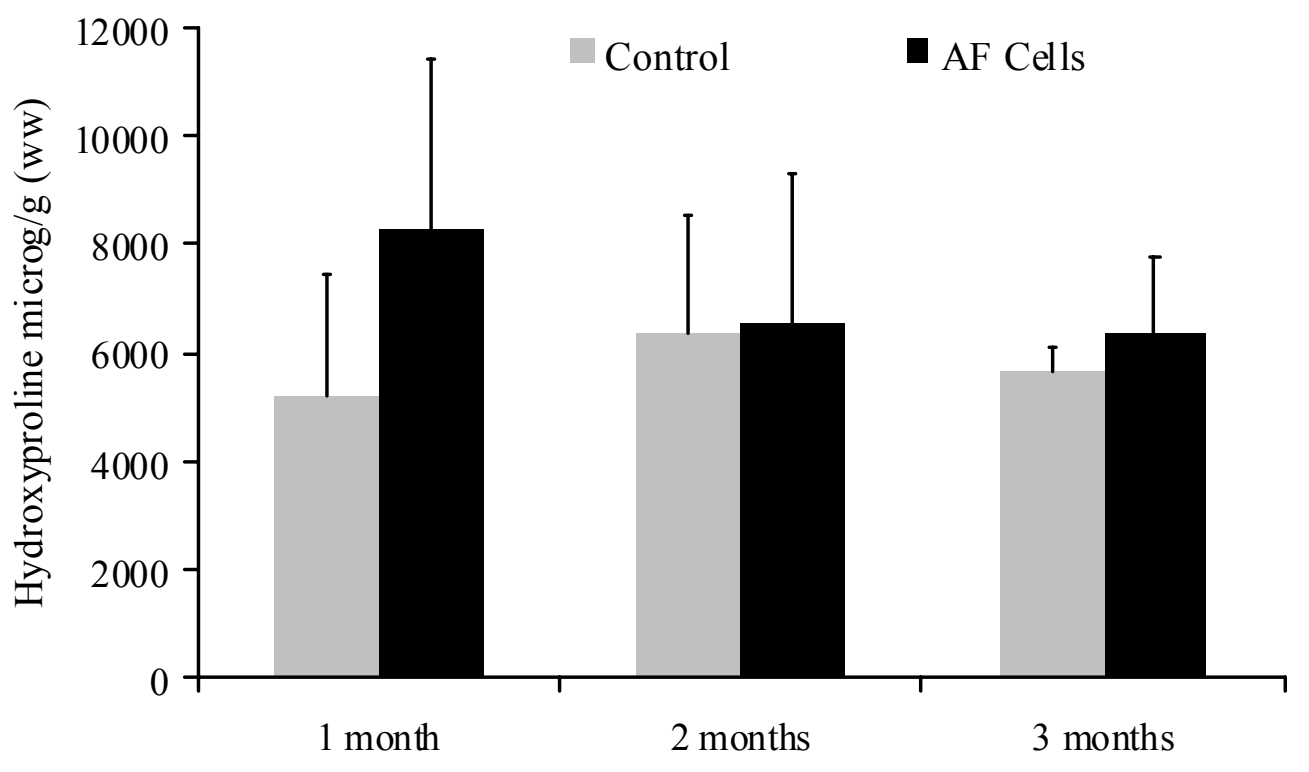


Fig.6
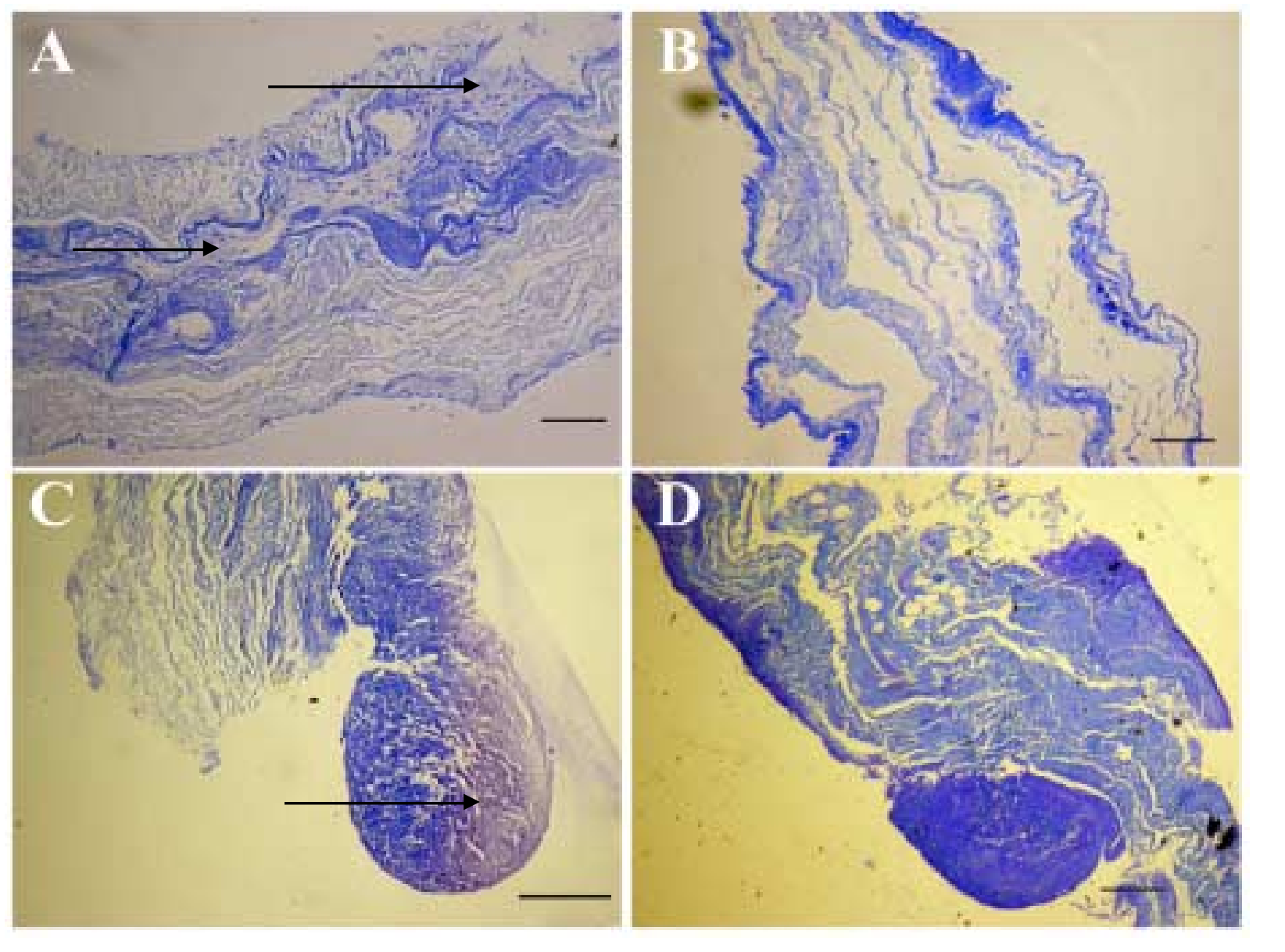
Fig.7

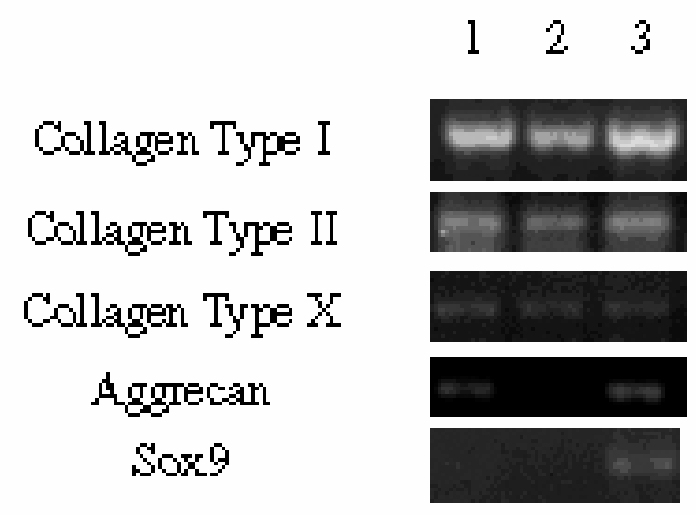

